\title{
Resúmen del XI Congreso de la Asociación Española de Ecología Terrestre
}

\author{
J.B. Imbert ${ }^{1}$, J.A. Blanco ${ }^{1, *}$ \\ (1) Universidad Pública de Navarra, Pamplona, Navarra, 31006 \\ * Autor de correpondencia: J.A. Blanco [juan.blanco@unavarra.es]
}

> Recibido el 1 de agosto de 2013, aceptado el 26 de agosto de 2013

Imbert, J.B., Blanco, J.A. (2013). Resúmen del XI Congreso de la Asociación Española de Ecología Terrestre. Ecosistemas 22(2):126-127.

Doi.: 10.7818/ECOS.2013.22-2.21

Entre el 6 y el 10 de Mayo de 2013, la Asociación Española de Ecología Terrestre celebró con gran éxito su reunión bianual en la Universidad Pública de Navarra, en Pamplona (Fig. 1). El congreso atrajo a casi 300 inscritos entre investigadores, docentes, estudiantes y profesionales de la ecología procedentes de 14 países, y hubo una amplia afluencia de público no especializado en las actividades abiertas al público general. El principal objetivo de la conferencia, como se indica su lema "Invitación a la ecología: estrechando lazos con la sociedad" fue no solo compartir los últimos avances en ecología entre los científicos, sino también promover el contacto entre científicos y la sociedad. El sentir general ha sido de congratulación por el alto nivel general de las ponencias científicas, y por el ambiente propicio para procurar transferencias de conocimientos, opiniones y servir de germen para el diseño de nuevos e interesantes proyectos.

En la parte Científica del congreso, los asistentes intercambiaron sus ideas por medio de 186 presentaciones orales, 84 posters y varias mesas redondas, divididos en 11 sesiones temáticas que cubrieron los campos de investigación de la ecología actual. Además, los ponentes plenarios invitados (Pedro Jordano, Miguel Verdú, Anna Traveset y Stefan Schnitzer) acercaron los últimos avances en sus respectivos campos de la ecología a los asistentes al congreso y al público general (Tabla 1). El congreso también acogió el simposio abierto al público general "Ecología y Sociedad", continuando el esfuerzo creciente de la AEET para divulgar el conocimiento ecológico y sensibilizar sobre los problemas ambientales, tanto locales como globales. El simposio contó con: 1) dos ponencias invitadas sobre "Economía verde y Sostenibilidad" coordinadas por el Foro para la Sostenibilidad de Navarra, 2) una ponencia invitada sobre el "Uso del Aprendizaje basado en Problemas y Proyectos en la enseñanza de la Ecología", 3) tres ponencias invitadas orientadas a mejorar la comunicación de la ciencia de la ecología a estudiantes y la sociedad en general, y 4) tres ponencias invitadas sobre conservación y gestión de árboles viejos y bosques maduros (Fig. 2).

El simposio concluyó con un debate abierto a todo el público alrededor de un tema que aparece continuamente en los titulares de los medios de comunicación "¿Deberíamos preocuparnos por el cambio global?". Expertos en climatología, energía, y ecología respondieron a las preguntas del público sobre este tema. Las posturas de cada experto pueden verse en el enlace que se proporciona abajo.

El congreso acogió otras actividades como los concursos de vídeo y fotografía en los que los participantes debían responder a

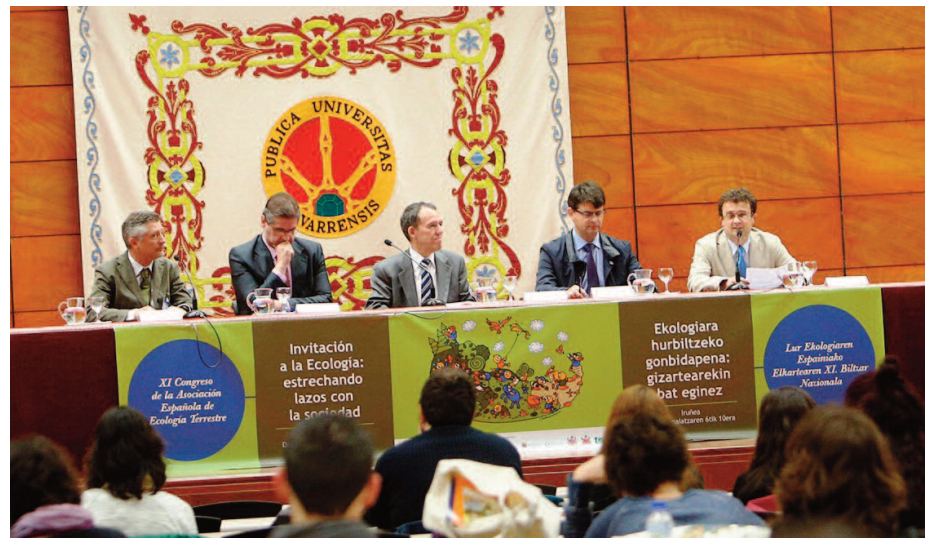

Figura 1. Ceremonia de apertura. De derecha a izquierda: Dr. Fernando Valladares (presidente de la AEET), D. Andrés Eciolaza (Director General del Servicio de Medio Ambiente y Agua del Gobierno de Navarra), Dr. Julio Lafuente (Rector de la UPNA), y Dr. J. Bosco Imbert (Coordinador general del comité organizador).

las preguntas “¿Qué hacen los ecólogos?” y “¿Qué estudian los ecólogos?" utilizando vídeos de un minuto realizados con un teléfono móvil o fotografías digitales acompañadas por un breve texto, respectivamente. Los trabajos ganadores se mostraron en una exposición de fotografía durante el congreso y la cena de clausura, y están disponibles en la web de la AEET (www.aeet.org).

Como actividad final, los asistentes visitaron dos bosques emblemáticos de los Pirineos occidentales en Navarra: Irati (el segundo hayedo más grande de Europa) y Larra (uno de los ejemplos más importantes de paisajes kársticos de Europa Occidental). Los asistentes a las excursiones disfrutaron no sólo de la belleza de los paisajes, sino también de las explicaciones de los guardas y guías locales sobre la historia y el manejo de los ecosistemas en cada lugar (Fig. 3). Fotografías adicionales de las excursiones pueden verse también en la web de la AEET.

Desde el comité organizador, queremos agradecer a todos los asistentes su participación, y esperamos que ellos hayan disfrutado del congreso tanto como los organizadores.

Dr. J. Bosco Imbert, coordinador general del comité organizador Dr. Juan A. Blanco, coordinador del comité científico 
Tabla 1. Enlaces permanentes en UPNA TV a las ponencias plenarias y a la mesa redonda de clausura.

\begin{tabular}{lll}
\hline \multicolumn{1}{c}{ Ponente } & \multicolumn{1}{c}{ Titulo } & Enlace \\
\hline $\begin{array}{lll}\text { Pedro Jordano } \\
\text { Estación Biológica de Doñana (CSIC) }\end{array}$ & $\begin{array}{l}\text { Otra biodiversidad: genes, interacciones y } \\
\text { servicios ecológicos en un mundo cambiante }\end{array}$ & http://upnatv.unavarra.es/es/pub/pedro-jordano \\
\hline $\begin{array}{l}\text { Miguel Verdu } \\
\text { Centro para la investigación en Desertificación }\end{array}$ & $\begin{array}{l}\text { Colapso ecosistémico debido al impacto hu- } \\
\text { mano en múltiples redes ecológicas }\end{array}$ & http://upnatv.unavarra.es/es/pub/miguel-verdu \\
\hline $\begin{array}{l}\text { Stefan Schnitzer } \\
\text { University of Wisconsin-Milwakee (EEUU) }\end{array}$ & $\begin{array}{l}\text { Trees, lianas and the maintenance of species } \\
\text { Diversity in tropical forests }\end{array}$ & http://upnatv.unavarra.es/es/pub/stefan-schnitzer \\
\hline $\begin{array}{l}\text { Anna Traveset } \\
\text { Institut Mediterraní d'Estudis Avançats (CSIC, UIB) }\end{array}$ & $\begin{array}{l}\text { Impactos del cambio global en las interaccio- } \\
\text { nes bióticas: una perspectiva de comunidad }\end{array}$ & http://upnatv.unavarra.es/es/pub/anna-traveset \\
\hline $\begin{array}{l}\text { Rafael Aldai } \\
\text { Centro de Recursos Ambientales de Navarra }\end{array}$ & $\begin{array}{l}\text { ¿Deberíamos preocuparnos por el cambio } \\
\text { global? }\end{array}$ & http://upnatv.unavarra.es/es/pub/mesa-aeet \\
$\begin{array}{l}\text { Josep-Antón Morguí } \\
\text { Institut Català de Ciències del Clima }\end{array}$ & & \\
$\begin{array}{l}\text { Anna Traveset } \\
\text { Institut Mediterraní d'Estudis Avançats (CSIC, UIB) }\end{array}$ & \\
$\begin{array}{l}\text { Fernando Valladares } \\
\text { Museo Nacional de Ciencias Naturales }\end{array}$ \\
$\begin{array}{l}\text { Moderador: Adolfo Gallego } \\
\text { Radiotelevisión Española en Navarra }\end{array}$ \\
\hline
\end{tabular}

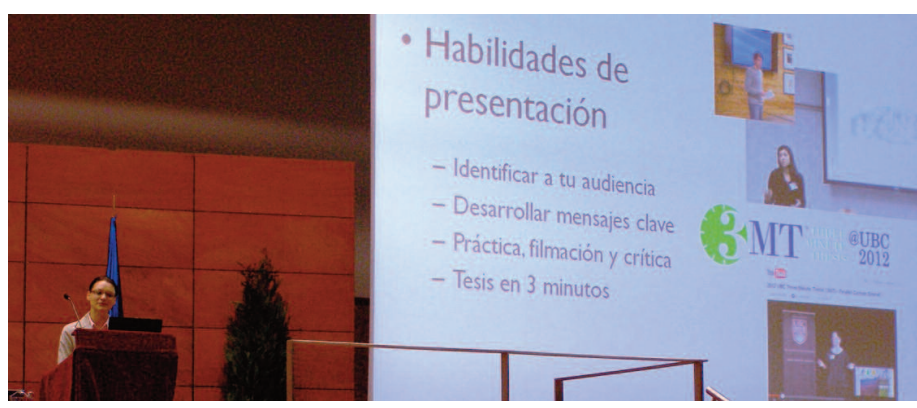

Figura 2. Dra. Julia Dordel (University of British Columbia), presentando el programa de estudios de postgrado TerreWEB, para habilitar a estudiantes graduados en la comunicación de la ciencia del cambio global.

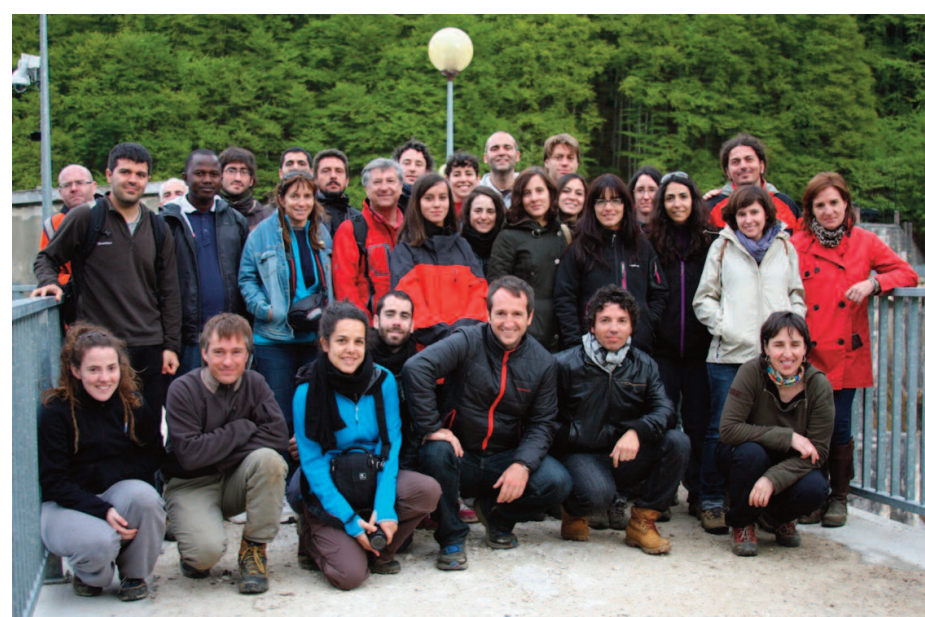

Figura 3. Participantes en la excursión al bosque de Irati (Pirineos occidentales). 